\title{
Cadeias de Markov e tecnologias digitais: reflexões sobre a construção de conhecimentos dos discentes em licenciatura em Matemática
}

\author{
Markov chains and digital technologies: reflections \\ on the construction of students' knowledge in degree \\ in Mathematics teaching
}

\author{
Rodrigo Sychocki da Silva ${ }^{1}$ \\ https://orcid.org/0000-0002-7406-2517 \\ Dante Augusto Couto Barone ${ }^{2}$ \\ https://orcid.org/0000-0002-5133-0144 \\ Marcus Vinícius de Azevedo Basso ${ }^{1}$ \\ https://orcid.org/0000-0002-2312-9056
}

\begin{abstract}
Resumo: $\mathrm{O}$ artigo expõe o recorte de uma pesquisa de doutorado que investigou o processo de construção de conceitos matemáticos por estudantes que fizeram o uso das tecnologias digitais. O público participante da pesquisa foram estudantes da graduação em Licenciatura em Matemática de uma instituição federal de ensino superior. A inspiração para a organização e para o percurso metodológico foi a engenharia didática de M. Artigue e utilizou-se como referencial teórico, para analisar a produção dos participantes, a teoria da abstração reflexionante de Piaget. Por meio do experimento didático na presente pesquisa, infere-se que o uso das tecnologias digitais oportunizou aos participantes o desenvolvimento e a manutenção de formas de pensamento nas quais foi possível que cada um dos envolvidos construísse e desenvolvesse os seus próprios significados para os conceitos matemáticos estudados.
\end{abstract}

Palavras-chave: Ensino de matemática. Ensino superior. Aprendizagem. Engenharia didática. Tecnologia digital

\begin{abstract}
The article shows the essence doctoral research that investigated the process of construction of mathematical concepts by students who made use of the Digital Technologies. The audience participating in this phase of the survey were students of the undergraduate degree in Mathematics Teaching (called 'Licenciatura' in Brazil) from a federal teaching institution. The inspiration for the organization and methodological course is the Didactic Engineering of M. Artigue and it was used as theoretical reference to analyze the production of the participants the theory of reflective abstraction of J. Piaget. Through the didactic experiment in the present research it is inferred that the use of Digital Technologies gave the participants the opportunity to develop and maintain forms of thought which allowed each one of them to construct and develop their own meanings for the study of mathematical concepts.
\end{abstract}

Keywords: Mathematics teaching. Higher education. Learning. Didactic engineering. Digital technology.

\footnotetext{
${ }^{1}$ Universidade Federal do Rio Grande do Sul (UFRGS), Instituto de Matemática, Departamento de Matemática Pura e Aplicada, Porto Alegre, RS, Brasil. E-mail: <rodrigo.sychocki@ufrgs.br>.

${ }^{2}$ UFRGS, Instituto de Informática, Departamento de Informática Aplicada, Porto Alegre, RS, Brasil.
} 


\section{Introdução}

D’Ambrosio (1996) considera a matemática uma ciência complexa já que requer tempo até que os estudantes tenham a compreensão dos conceitos. Destaca que, além das aplicações inerentes à própria matemática, seja também plausível que os conceitos abordados nesta disciplina sejam compreendidos pelos estudantes como aplicáveis à sua vida cotidiana ou profissional. As Cadeias de $\mathrm{Markov}^{3}$ são usadas em aplicações em áreas da ciência tais como: geografia, biologia, administração, economia, química e na própria matemática. Nessas áreas do conhecimento, as Cadeias de Markov são usadas para descrever um modelo matemático que é realizado diversas vezes da mesma maneira, por meio de uma sequência de etapas, as quais estão relacionadas em sucessivas iterações.

A escolha e adaptação dos fenômenos estudados e o uso da Tecnologia Digital foram fundamentais para o desenvolvimento desta pesquisa de doutorado, que ocorreu em três momentos distintos. Percebeu-se que as diretrizes oficiais para o Ensino Médio propõem que a organização curricular seja de caráter interdisciplinar, porém o que se observa ainda é o ensino fragmentado dos conteúdos de matemática, não oportunizando ao estudante perceber a importância da matemática na modelagem de situações-problema que são observáveis nos fenômenos da ciência.

As Diretrizes curriculares nacionais gerais da educação básica (BRASIL, 2013, p. 244), atestam que "a organização curricular deve fundamentar-se em metodologia interdisciplinar que rompa com a fragmentação do conhecimento e a segmentação presentes na organização disciplinar tradicionalmente adotada de forma linear". Nesse caso, a interdisciplinaridade deve ser contemplada além da mistura de componentes curriculares, abrindo-se à possibilidade de relacionar atividades, projetos, pesquisa e ação, para oportunizar uma formação plural dos egressos de determinado curso.

O interesse em promover e valorizar a interdisciplinaridade também é manifestado no parecer das Diretrizes curriculares nacionais para a formação inicial e continuada dos profissionais do magistério da educação básica (BRASIL, 2015). No documento, percebe-se uma intencionalidade quanto às formas de elaboração e construção do conhecimento, sugerindo-se que elas não ocorram de forma isolada e fragmentada. Na matemática, em especial, durante a formação inicial do professor, é importante que a interdisciplinaridade seja valorizada e, assim, oportunize a construção dos conhecimentos matemáticos, implicando em futuras contribuições na matemática desenvolvida na sua sala de aula.

Nesse sentido, por meio de sequências de atividades que fazem uso de recursos tecnológicos, foram utilizados objetos virtuais para acompanhar a evolução dos sujeitos durante a investigação de situações-problema envolvendo Cadeias de Markov. Ao longo da tese de doutorado, buscou-se refletir e compreender como os sujeitos envolvidos construiriam mode-

\footnotetext{
${ }^{3}$ Para mais detalhes matemáticos sobre esse assunto consulte Anton e Rorres (2012), Anton e Busby (2003) e Behrends (2000). O nome Cadeia de Markov foi dado em homenagem ao matemático russo Andrei Andreyevich Markov que as criou inicialmente em 1907.
} 
los matemáticos capazes de explicar o fenômeno estudado, a partir de ações e coordenações de ações sobre os objetos envolvidos, sejam materiais, virtuais ou mentais. Nosso estudo foi norteado pela seguinte questão: Como evolui a abstração refletida (abstração reflexionante com tomada de consciência), na construção de conceitos matemáticos durante a exploração de situações-problema de modelagem matemática com Cadeias de Markov em uma sequência didática usando objetos virtuais? Entendeu-se que o uso da tecnologia seria uma possibilidade/meio/recurso de o sujeito agir sobre o objeto de conhecimento, tornando possível o estabelecimento de relações que permitiriam a construção de conceitos matemáticos. A teoria da abstração reflexionante, proposta por Piaget (1977), foi uma ferramenta importante na tese para analisar a evolução dos sujeitos envolvidos com a proposta, e a inspiração na Engenharia Didática de Artigue (1996) oportunizou esboçar o caminho metodológico a ser usado na pesquisa.

A intenção do presente texto é apresentar e discutir os resultados do último experimento didático (fase 3, de um total de 3) da pesquisa de doutorado de Silva (2015), a qual argumenta que a construção do conhecimento matemático ocorre como resultado da combinação dos fatores: (1) evolução da atividade cognitiva do sujeito, manifestada pelo aperfeiçoamento no processo da abstração; (2) aperfeiçoamento da ação do sujeito sobre os objetos; (3) uso da tecnologia como parceira no estabelecimento de relações entre o sujeito e o objeto do conhecimento, potencializando a análise, interpretação e construção de modelos matemáticos com o auxílio do computador. O artigo está organizado da seguinte forma: uma breve revisão de literatura sobre Tecnologias Digitais e Modelagem Matemática, necessária para a compreensão do contexto da pesquisa; uma seção sobre os conceitos de Epistemologia Genética usados na análise das produções; caracterização metodológica com exposição dos materiais e métodos utilizados; um recorte com produções e análises; e, por fim, tecem-se reflexões sobre o experimento didático e contribuições da tese para o campo da Educação Matemática.

\section{Tecnologias digitais e modelagem matemática}

Esta seção apresenta e reflete sobre estudos que contribuem para a discussão que envolve uso das tecnologias digitais nas aulas de matemática. Argumenta-se que, ao fazer uso das tecnologias, o processo envolve uma aprendizagem múltipla, na qual todos os envolvidos constroem conceitos por meio do estabelecimento e manutenção de relações com os objetos de conhecimento e estudos envolvidos.

No contexto da nossa pesquisa, a Tecnologia Digital surgiu como uma variável em potencial para colaborar no processo de transformação dos sujeitos. Almeida, Silva e Vertuan (2012) defendem o uso das mídias digitais, em especial nas investigações envolvendo Modelagem Matemática. Como justificativas plausíveis, os autores consideram que o uso da tecnologia "permite que a maior parte dos esforços se concentre nas ações cognitivas associadas ao desenvolvimento da atividade de modelagem, considerando que a realização de cálculos, aproximações e representações gráficas é mediada pelo uso do computador" (ALMEIDA; SILVA; VERTUAN, 2012, p. 32).

Quanto à dinâmica das transformações, Powell (2014) faz uma observação que relaciona a velocidade com que a tecnologia e as inovações ocorrem ao desenvolvimento e aperfeiçoamento de novos produtos tecnológicos: 
O primeiro desafio trata da velocidade das mudanças tecnológicas e a necessidade de que pesquisadores e educadores investiguem como aproveitar as novas tecnologias. (...) Associado à rapidez dos avanços das tecnologias de informação e comunicação, o segundo desafio está relacionado com a necessidade de colaboração para encontrar soluções relativas ao design de projetos e desenvolvimento de novos produtos, mídias e serviços para melhorar a vida do planeta e de seus habitantes. Argumentamos que há três aspectos relativos à produção de conhecimentos que o mundo atual privilegia: (1) a interação interpessoal e social, (2) a resolução de problemas e (3) a comunicação. (POWELL, 2014, p. 14).

Em contraste com a velocidade na evolução da tecnologia, Tall (1999, p. 4) reflete que, antes da popularização do computador, os sujeitos precisavam realizar todos os cálculos aritméticos e algébricos manualmente, sendo que hoje tudo pode ser feito sem esforço, com o auxílio do computador. O autor reflete que, para o "especialista", isso é maravilhoso, porém, questiona-se como o raciocínio matemático é influenciado pelo uso da tecnologia para o "novato".

Sobre as considerações de Tall (1999), duas reflexões são feitas. A primeira, acerca do uso das tecnologias por sujeitos especialistas. Nesse caso, a tecnologia seria o catalisador de um trabalho que antes era desenvolvido manualmente. Naturalmente, os sujeitos (especialistas) previamente conhecem a teoria matemática envolvida no contexto em estudo e possivelmente usarão a tecnologia como uma ferramenta na construção de novos conhecimentos. O segundo aspecto manifestado pelo autor trata de como o uso das tecnologias impacta as formas de raciocínio matemático desenvolvidas pelos "novatos". Considera-se que a expressão "novato" esteja sendo utilizada pelo autor para designar o sujeito aprendiz, o qual não necessariamente conheça os conteúdos e as construções conceituais matemáticas para resolver determinado desafio imposto pelos problemas. Logo, a partir da questão proposta pelo autor, poderíamos questionar-nos se o uso do computador por tipos diferentes de sujeitos oportuniza-lhes, de fato, momentos diferentes de aprendizagem. No conjunto de pesquisas consultadas (ALLEVATO, 2005; ALMEIDA; SILVA; VERTUAN, 2012; ARAÚJO, 2002; BORSSOI, 2013; MALHEIROS, 2004; POWELL, 2014; SOARES, 2012; SOISTAK, 2010; TALL, 1986, 1999; TALL; DUBINSKY, 1991), verificou-se que a tecnologia oportuniza e potencializa, em inúmeros sentidos, a todos os sujeitos envolvidos a construção de relações e, consequentemente, a aprendizagem.

Sobre o uso de computadores, Tall (1986) afirma que, em aspectos de aprendizagem, há a inserção de uma nova dimensão. Considerando-se o tripé constituído pelas dimensões professor - matemática - estudante, o computador passaria a constituir um quarto elemento que se relaciona com os outros três já existentes. Tall (1986) define, então, uma estrutura chamada de tetraedro pedagógico, na qual, a partir das quatro dimensões (professor - matemática - estudante - computador), pode-se, em determinado contexto, oportunizar que novas relações e caminhos sejam construídos durante o processo de aprendizagem. No contexto de pesquisa apresentado neste artigo, o estudante está representado pelo graduando em Licenciatura em Matemática. A Figura 1 apresenta a estrutura do tetraedro pedagógico proposto por Tall (1986, p. 26). 
Figura 1. Tetraedro pedagógico proposto por Tall (1986)

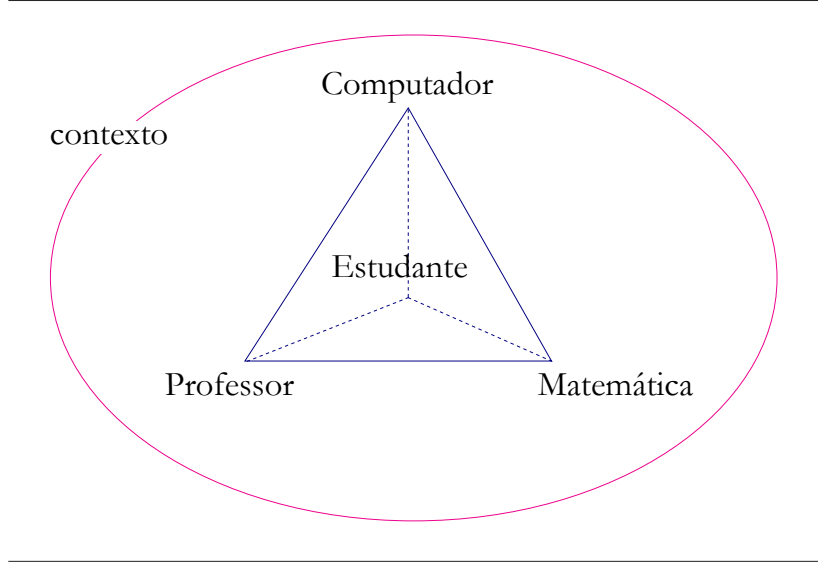

Fonte: Tall (1986, p. 26).

Tall e Dubinsky (1991) afirmam que, a partir de um determinado contexto, a aprendizagem dos estudantes é influenciada pela sua atividade mental desempenhada sobre os objetos em estudo. Tais atividades são potencializadas no uso adequado do computador, quando o professor pode estimular e desafiar os estudantes na construção de seu próprio conhecimento. Segundo os autores, ao fornecer um software "ricamente dotado que incorpora ideias matemáticas poderosas para que o aluno possa manipular e refletir sobre elas" (TALL; DUBINSKY, 1991, p. 235, tradução nossa), oportuniza-se que, por meio das diversas situações, seja possível ao estudante construir conceitos de matemática. Nesse sentido, Tall (1999) contribui enfatizando que, ao fazer uso das tecnologias, o professor deve observar e perceber como os estudantes desenvolvem e constroem ideias matemáticas. Segundo o autor, a elaboração de imagens mentais contribui para o processo de construção de conceitos matemáticos e deve ser considerado pelo professor ao propor desafios e situações que façam uso da tecnologia durante sua exploração.

As pesquisas consultadas e citadas anteriormente procuram refletir e discutir o contraste no uso das Tecnologias Digitais em relação aos métodos e materiais usados em sala de aula. Nota-se que os autores consultados convergem para a ideia de que, ao fazer uso das Tecnologias Digitais, oportuniza-se que sejam elaborados pelos sujeitos diversos experimentos de pensamento, que os qualificam e os direcionam para uma aprendizagem singular e propriamente individual, resultado da ação de cada sujeito sobre os objetos em estudo. Ou seja, a cada passo em que a investigação matemática avança - no sentido da compreensão do objeto de conhecimento ou fenômeno em estudo - professor e estudantes (re)constroem e (re)significam as ideias, potencializando qualitativamente o momento de aprendizagem e a construção de novos conceitos matemáticos.

\section{Epistemologia genética de Piaget: abstração e tomada de consciência}

O estudo da tomada de consciência e da abstração, proposta por Jean Piaget, concentrase nas obras A tomada de consciência (1977), Fažer e compreender (1978) e Abstração reflexionante (1995), 
nas quais o autor apresenta e discute os principais conceitos e aspectos teóricos. Tais conceitos foram importantes na análise da produção dos sujeitos envolvidos em todos os experimentos didáticos da tese, em particular o apresentado neste texto.

A evolução dos níveis da tomada de consciência ocorre junto com o progresso da abstração. Há relações mútuas entre abstração e tomada de consciência. A melhora qualitativa de um aspecto implica a melhora qualitativa do outro, ou seja, quanto mais elaborados se tornam os níveis de abstrações, melhores são os níveis de tomada de consciência, os quais auxiliam na compreensão de como o conhecimento lógico-matemático é construído, organizado e estruturado pelo sujeito durante sua ação sobre o objeto.

A Epistemologia Genética considera como hipótese, para explicar a gênese do desenvolvimento cognitivo humano, a necessidade da ação do sujeito sobre os objetos e seus sucessivos avanços, devido à organização das coordenações das ações realizadas pelo próprio sujeito. O termo coordenações de ações é a fonte dos dados no processo de abstração proposto por Piaget (1995). $\mathrm{O}$ verbo abstrair significa retirar, extrair, puxar. Nesse caso, temos que a abstração consiste no processo de retirada de qualidades dos objetos (abstração empírica) ou também de retirada de qualidades das coordenações de ações (abstração reflexionante). Nesse sentido, a abstração divide-se em duas categorias gerais: abstração empírica e abstração reflexionante.

Logo, pode-se afirmar que a abstração empírica consiste em extrair dos objetos qualidades que eles têm, por meio das quais o sujeito terá a possibilidade de estabelecer relações e elaborar novas características ou qualidades para os objetos. Portanto, a abstração empírica é uma etapa inicial e necessária para a evolução cognitiva do sujeito, uma vez que sem ela não é possível desenvolver qualitativamente o pensamento através dos níveis da abstração reflexionante.

Não se pode confundir o processo de retirada das características dos objetos com a retirada de qualidades que se atribuem aos objetos, caracterizada por Piaget (1977) como abstração pseudo-empírica. Esse é um tipo de abstração reflexionante na qual o sujeito exerce a coordenação de suas ações para que ela ocorra. Sobre esse tipo de abstração, Becker (2014) esclarece:

A abstração pseudo-empírica consiste em retirar dos observáveis não suas características, mas aquilo que o sujeito colocou neles. Por ela, o sujeito projeta no mundo dos observáveis suas coordenações de ações. Ao retirar características dos observáveis, não retira o que pertence aos observáveis - como na abstração empírica, mas o que ele, sujeito, colocou neles. (BECKER, 2014, p. 114).

No contexto da pesquisa aqui exposta, não se pode desvincular do processo de construção do conhecimento pelo sujeito o papel desempenhado pelas abstrações pseudo-empíricas. Trata-se de um complexo jogo de relações predominantemente mentais estabelecidas entre as abstrações empíricas e abstrações reflexionantes, as quais, a partir da ação e do melhoramento destas pelo sujeito, evocam-se simultaneamente qualidades inerentes aos dois tipos de abstrações mencionados anteriormente. O exercício da abstração de qualidade pseudo-empírica, quando desempenhado pelo sujeito, oportuniza que uma articulação entre esses dois tipos de abstração seja feita, valorizando e aperfeiçoando o processo de ação e coordenação de ações sobre os objetos. Esse exercício de articulação, na forma de um binômio, ocorre conforme mostra Becker (2014, p. 119): 
A abstração pseudo-empírica articula a passagem entre a abstração empírica e a reflexionante. Como reflexionante, ela reconhece a legitimidade da abstração empírica mas, ao mesmo tempo, mostra que é a reflexionante que organiza, dá sentido aos dados obtidos pela empírica. A condição de possibilidade da abstração empírica reside nos instrumentos que a abstração reflexionante vai construindo e pondo a sua disposição.

No estudo da matemática, a pseudo-empírica se faz presente, ao passo que a extração das características impostas pelos sujeitos é necessária e contribui para elaborações mais complexas que generalizam as qualidades, enriquecendo, assim, o objeto de estudo. À medida que se aumenta o número de abstrações do sujeito, durante o processo interativo sujeito-objeto, a qualidade de seu pensamento evolui devido ao progresso da abstração reflexionante e às sucessivas tomadas de consciência que daí decorrem. O conhecimento matemático é construído por abstração reflexionante, sobretudo pela pseudo-empírica. Destaca-se que a abstração empírica, sozinha, não constrói conhecimento (capacidade) matemático.

A abstração reflexionante tem duas características essenciais para a compreensão de como os níveis de abstração e tomada de consciência progridem no decorrer da ação do sujeito. Trata-se dos processos de reflexionamento e reflexão. Sobre isso, Piaget (1995, p. 274) afirma:

Lembremo-nos, igualmente, de que a abstração reflexionante comporta sempre, dois aspectos inseparáveis: de um lado, "reflexionamento" (réfléchissement), ou seja, a projeção (como através de um refletor) sobre um patamar superior daquilo que foi tirado do patamar inferior e, de outro lado, uma "reflexão" (réflexion), entendida esta como ato mental de reconstrução e reorganização sobre o patamar superior daquilo que foi assim transferido do inferior.

A união da reflexão e do reflexionamento constitui uma estrutura capaz de não apenas passar de um nível para o seguinte, mas de, juntas, terem o caráter de uma estrutura capaz de desenvolver características qualitativas superiores no decorrer das passagens ou projeções. Isso significa que os patamares superiores alcançados pelo sujeito, através da ação e coordenação de suas ações, têm relação intrínseca com os patamares inferiores ou iniciais desenvolvidos através da ação.

Portanto, é por meio de sucessivas operações de reflexão e reflexionamento que é possível ao sujeito avançar na direção dos patamares superiores de abstração e tomadas de consciência de maior qualidade. A reorganização e coordenação de suas ações lhe permitem qualificar cada vez mais a sua ação na busca pela compreensão do objeto, ou seja, a evolução da abstração reflexionante é um processo por meio do qual o sujeito constrói, reconstrói, organiza e reorganiza os seus esquemas e estruturas de pensamento a todo o momento.

A evolução da tomada de consciência, tal como a abstração, ocorre em níveis que progressivamente evoluem conforme aumenta a intensidade da interação entre sujeito e objeto. Pode-se afirmar que esses níveis estão em correspondência biunívoca com o processo de abstração, ao passo que a abstração - caracterizada pela tomada de consciência, independente do nível em que o sujeito está cognitivamente - é chamada de abstração refletida. Essa última é o 
produto de uma abstração reflexionante que se tornou consciente. As pesquisas apresentadas por Piaget (1995) mostram que, para atingir tal patamar de abstração, o sujeito deve passar por etapas que são necessárias e graduais, nas quais, a cada novo desafio, o sujeito é desequilibrado e deve se reorganizar de tal forma a superar as contradições e dificuldades que surgem na interação. A maneira de promover, por parte do sujeito, o avanço através dos diferentes níveis é desenvolver a regulação ativa, ou seja, desafiar a criação e o desenvolvimento de novidades frente às diversas situações.

Por fim, é imprescindível observar a influência da criação de novidades no processo, ou ainda as contribuições das regulações ativas para o processo da abstração reflexionante e, consequentemente, para a tomada de consciência. Sobre tal influência, Piaget (1995) afirma que há relação direta entre os reflexionamentos e as construções das novidades, de forma que o enriquecimento de um implica o enriquecimento do outro. Ou seja, uma melhora qualitativa nas regulações ativas diante das situações de desequilíbrio está condicionada a melhores reflexionamentos e reflexões (reconstrução sobre um patamar superior daqui que fora dado no precedente $=$ reflexão) elaborados pelo sujeito.

\section{Procedimentos metodológicos: materiais e métodos}

Nesta seção, apresentam-se os procedimentos metodológicos, materiais e métodos utilizados no decorrer da pesquisa, e justifica-se a inspiração e o uso do conceito de Engenharia Didática de M. Artigue para o desenvolvimento da proposta.

A aplicação do terceiro experimento didático ${ }^{4}$ ocorreu com estudantes do ensino superior e aconteceu em um dos laboratórios de informática do Instituto Federal de Educação, Ciência e Tecnologia do Rio Grande do Sul (câmpus de Caxias do Sul), durante cinco semanas, nas aulas regulares da disciplina de Modelagem Matemática, no curso de Licenciatura em Matemática, no segundo semestre de 2015. Cada um dos encontros ocorreu de forma presencial e teve a duração de três horas e vinte minutos. Ocorreu, também, uma parte da sequência de atividades na forma semipresencial, na forma de um trabalho envolvendo o assunto. Os estudantes foram alocados de forma individual nos computadores, porém, por momentos, realizaram discussões e reflexões entre si, acompanhadas pelo professor. O uso dos objetos virtuais Cadeia de Markov - 2D e Cadeia de Markov - 3D $D^{6}$ ocorreu por meio da internet, e os registros escritos foram produzidos pelos estudantes de forma individual em papel, no material fornecido pelo professor. Após cada encontro, o material produzido por cada um dos seis estudantes da turma ${ }^{7}$ foi digitalizado e armazenado pelo professor para futura análise da produção. Sendo assim, o manuscrito individual de cada participante foi entregue de volta a cada um dos estudantes da turma.

\footnotetext{
${ }^{4} \mathrm{O}$ trabalho da tese de doutorado (SILVA, 2015) teve ao todo três fases de experimentação didática, as quais ocorreram em momentos distintos da pesquisa. As fases dois e três ocorreram na mesma instituição, porém com a participação de públicos-alvo diferentes. A fase dois ocorreu no ensino médio e a fase três no ensino superior.

${ }^{5}$ Disponível em: <https://www.geogebra.org/m/zGyxVhtT>. Acesso em: 5 jan. 2017.

${ }^{6}$ Disponível em: <https://www.geogebra.org/m/r2faYn2v>. Acesso em: 5 jan. 2017.

${ }^{7} \mathrm{Na}$ época de realização do experimento didático, a turma da disciplina de Modelagem Matemática era constituída de seis estudantes.
} 
A partir do uso do software GeoGebra foram construídos e disponibilizados, no repositório virtual do GeoGebra, pelo professor da disciplina - primeiro autor deste texto - dois objetos virtuais: Cadeia de Markov - 2D e Cadeia de Markov - 3D, ambos apresentados na Figura 2. Cada um deles tem dois ambientes de trabalho que, nas figuras, foram indicados por $[\mathrm{A}] \mathrm{e}[\mathrm{B}]$.

No espaço [A], é oportunizado ao sujeito que está manipulando os objetos virtuais visualizar geometricamente o que ocorre com a representação do vetor utilizado nos cálculos. $\mathrm{O}$ espaço da parte [B] consiste em uma janela predominantemente algébrica, onde há parâmetros que podem ser modificados e, consequentemente, alteram os resultados visualizados em [A]. Em [B], é possível que o sujeito explore a operação de potenciação envolvendo matrizes quadradas de ordem dois e três. Ainda é possível explorar o conceito de escala e suas consequências no estudo de situações-problema, motivadas a partir da diversidade dos fenômenos observados na realidade. A sequência de atividades utilizadas ao longo dos dias no terceiro experimento está disponível integralmente na tese de Silva (2015).

Figura 2. Layout do objeto virtual
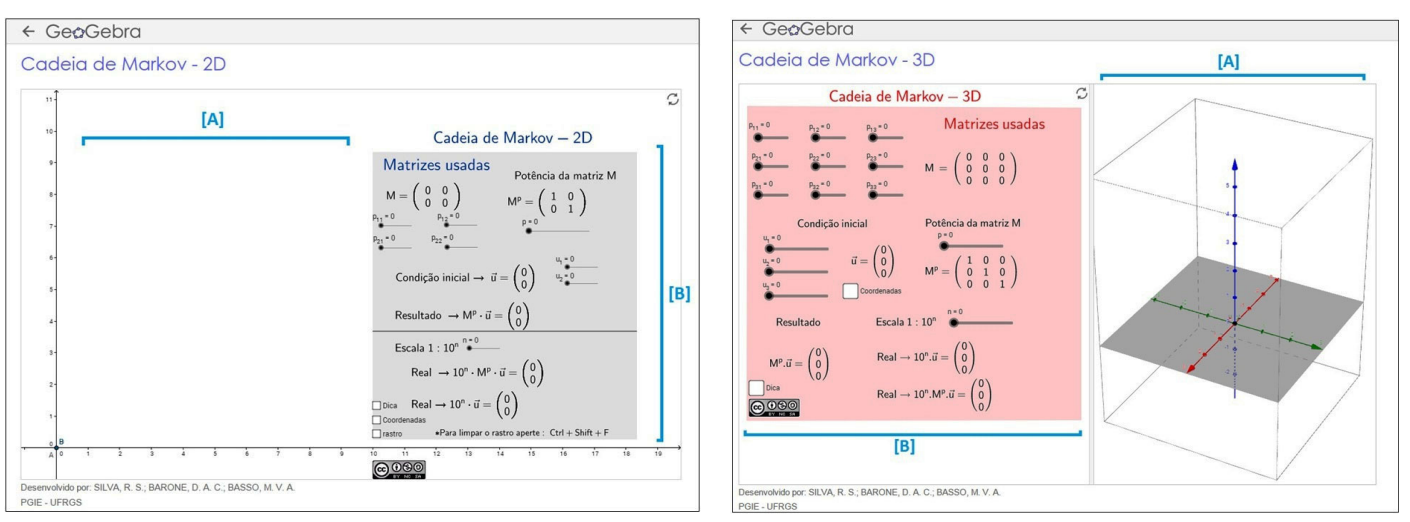

Cadeia de Markov - 2D (à esquerda) e Cadeia de Markov - 3D (à direita).

Fonte: Silva (2015, p. 85).

A sequência de atividades realizada no ensino superior foi organizada do seguinte modo: "Conbecendo o contexto" ( $\left.1^{\circ} \mathrm{dia}\right)$, "Conbecendo o objeto virtual" ( $2^{\circ}$ dia), "Retomando a problemática inicial" (3 dia), "Avançando no estudo da Cadeia de Markov - 2D" (4 dia), "Trabalho sobre Cadeias de Markov" (5" dia, modo semipresencial) e "Um pouco sobre Cadeias de Markov - 3D" (6" dia). Houve atividades semelhantes às utilizadas no ensino médio (segundo experimento), e isso permitiu que, por momentos, fossem estabelecidas relações entre as produções originadas a partir dos dois tipos de público participante. Para a construção e realização da sequência de atividades, inspiramo-nos metodologicamente na ideia de Artigue (1996) sobre Engenharia Didática, a qual afirma: 
1 - A engenharia didática vista como metodologia de investigação, caracteriza-se antes de mais nada por um esquema experimental baseado em "realizações didáticas" na sala de aula, isto é, na concepção, na realização, na observação e na análise de sequências de ensino. (...) 2-A metodologia de engenharia didática caracteriza-se ainda, relativamente a outros tipos de investigação baseados nas experimentações na sala de aula, pelo registro no qual se situa e pelos modos de validação que lhe estão associados. (ARTIGUE, 1996, p. 196).

Sobre a importância que a metodologia de investigação proposta pela Engenharia Didática desempenha para o professor durante seu trabalho, Artigue (1996, p. 197) expõe que "não é, pois, nos objetivos das investigações levadas a cabo sob o seu estandarte, mas nas características do seu funcionamento metodológico, que a engenharia didática apresenta a sua singularidade”. Ou seja, o professor, ao investigar o processo de aprendizagem por parte de seus alunos, tem, através dessa metodologia de trabalho, a oportunidade de avaliar e refletir sobre a sua própria atuação e participação como colaborador na criação e desenvolvimento do conhecimento.

A metodologia de trabalho, fundamentada nos princípios da Engenharia Didática, ocorre ao longo de um processo contínuo e constituído de níveis. A cada nível alcançado, o objeto do conhecimento investigado atinge determinado patamar, e os objetivos e propósitos do professor são repensados e reavaliados. Artigue (1996) propõe que a Engenharia Didática, durante o seu desenvolvimento, atravesse diferentes níveis, formas e graus de complexidade. A passagem de um nível para o seguinte constitui uma importante fonte de informações e de conhecimento para o professor. Os níveis, ou fases, propostos por Artigue (1996) como forma de organização são as seguintes: análises prévias (nível 1); concepção do experimento, análise a priori e elaboração das hipóteses (nível 2); experimentação (nível 3) e análise a posteriori juntamente com a validação e avaliação da proposta (nível 4).

Quanto às relações da Engenharia Didática com a proposta de trabalho, acredita-se que uma abordagem de situações-problema envolvendo Modelagem Matemática fazendo uso das Cadeias de Markov, a Engenharia Didática se desenvolveu da seguinte forma:

1. análise prévia - questionou-se sobre os métodos de ensino dos conteúdos propostos (matrizes e operações, probabilidade, vetores) e o processo de aprendizagem. Observaram-se, também, quais seriam as dificuldades apresentadas pelos estudantes perante tais conteúdos;

2. concepção do experimento, análise a priori e criação das hipóteses - criação da sequência de atividades que constituiu o experimento; formulação, por parte do professor, das hipóteses que seriam possivelmente validadas durante a execução das atividades;

3. experimento - execução das atividades planejadas na etapa anterior;

4. análise a posteriori - com base nas observações produzidas durante a fase da experimentação, o professor tentou validar ou não as hipóteses conjecturadas e assim validar o seu experimento didático.

Ao utilizar as ideias e conceitos da Engenharia Didática - na concepção de Artigue (1996), como inspiração para metodologia de investigação no trabalho de tese -, notou-se que 
os conceitos foram de considerável importância para o andamento da pesquisa. Os conceitos apresentados por Artigue constituem uma maneira progressiva e continuada que o professor tem de investigar aspectos da aprendizagem, a partir da ação dos estudantes mediante suas interações com os objetos de conhecimento propostos em uma determinada sequência de atividades. Ao explorar os níveis ou fases da Engenharia Didática, constatou-se a construção de um cenário de investigação complexo, no qual as ações e relações estabelecidas entre seus atores constituem importantes variáveis na compreensão pela construção do conhecimento em questão.

\title{
Recorte da produção dos sujeitos, análises e reflexões
}

Anteriormente afirmou-se que a sequência de atividades realizada no ensino superior foi organizada e ocorreu durante seis momentos distintos. A partir de agora, faz-se um recorte e expõe-se a produção dos sujeitos em dois momentos do experimento, $1^{\circ}$ e $4^{\circ}$ dias, pois, devido à limitação do presente artigo, não será possível explorar e detalhar todos os dias da sequência de atividades ${ }^{8}$.

No primeiro dia de atividades, na apresentação da situação-problema, os estudantes citaram os assuntos que, no entendimento deles, seriam os conteúdos matemáticos possivelmente utilizados na construção de uma solução para o problema. Os assuntos citados pela turma foram porcentagem (4 citações), adição (3 citações), subtração (3 citações), regra de 3 (2 citações), proporção (2 citações), razão (2 citações), equação (2 citações), multiplicação (2 citações), álgebra (matrizes) (1 citação), função afim (1 citação) e taxa de variação (1 citação).

\section{Situação-problema do primeiro dia}

\begin{abstract}
Suponha que no ano 2010 a taxa de migração de Caxias do Sul para o seu subúrbio seja de 7\%. E que duarante o mesmo ano a taxa de migração do subúrbio para a cidade seja de 4\%. Se a população observada no ano de 2010 foi de 350.000 habitantes na cidade e no subúrbio foi de 100.000 habitantes então qual a população estimada para o ano 2011 para cada um dos lugares?
\end{abstract}

Sobre a enumeração dos assuntos matemáticos anteriores, percebem-se semelhanças e diferenças com o ocorrido no experimento dois (ensino médio). Duas semelhanças são estas: (1) os dois públicos alvos distintos, em momentos diferentes, fizeram citações idênticas sobre qual conteúdo matemático seria possivelmente utilizado; (2) a citação de algum conteúdo matemático passa por um processo de organização conceitual do sujeito para o qual é necessário mobilizar diferentes estruturas que estão previamente organizadas e que agem na direção de tentar assimilar o objeto em estudo. Isso significa que, para ter mencionado o conteúdo porcentagem, por exemplo, o sujeito deve ter-se deparado com situações anteriores a esta e que o fizeram elaborar

\footnotetext{
${ }^{8} \mathrm{Na}$ tese de Silva (2015), estão detalhadas as análises dos seis momentos da sequência de atividades.
} 
e desenvolver um conjunto de ações que objetivassem auxiliá-lo nesta construção conceitual. O fato é que, diante de uma nova situação que se impõe ao sujeito, ele mobiliza diferentes esquemas assimiladores que agem na direção da diferenciação/integração das formas e dos conteúdos.

Observaram-se duas diferenças em relação ao experimento didático realizado no ensino médio: (1) não houve alguma identificação da situação-problema com funções exponenciais, as quais são usualmente usadas para analisar variações em crescimento/decrescimento populacionais; (2) presença e destaque de quais operações deveriam ser feitas, em oposição à citação apenas de conteúdo. Enquanto que os estudantes do ensino médio citaram mais conteúdos específicos de matemática, os estudantes do ensino superior citaram operações matemáticas a serem realizadas.

$\mathrm{Na}$ obtenção das estimativas populacionais, os pensamentos da turma como um todo convergiram e tiveram o encaminhamento adequado. Todos os envolvidos conseguiram, por meio de operações matemáticas, obter resultados satisfatórios para os questionamentos. Merece destaque o fato de que, ao fazer o processo de elaboração das estimativas, os sujeitos perceberam que o processo se tratava de iterações sucessivas, nas quais a $n$-ésima estimativa dependia da (n-1)-ésima. Com isso, a elaboração de um possível princípio geral foi norteada por esse pensamento. A Figura 3 ilustra a construção de dois estudantes ([S.2] e [S.4]) para um possível princípio geral.

Figura 3. Estimativas e anúncio de um princípio geral por [S.2] e [S.4]
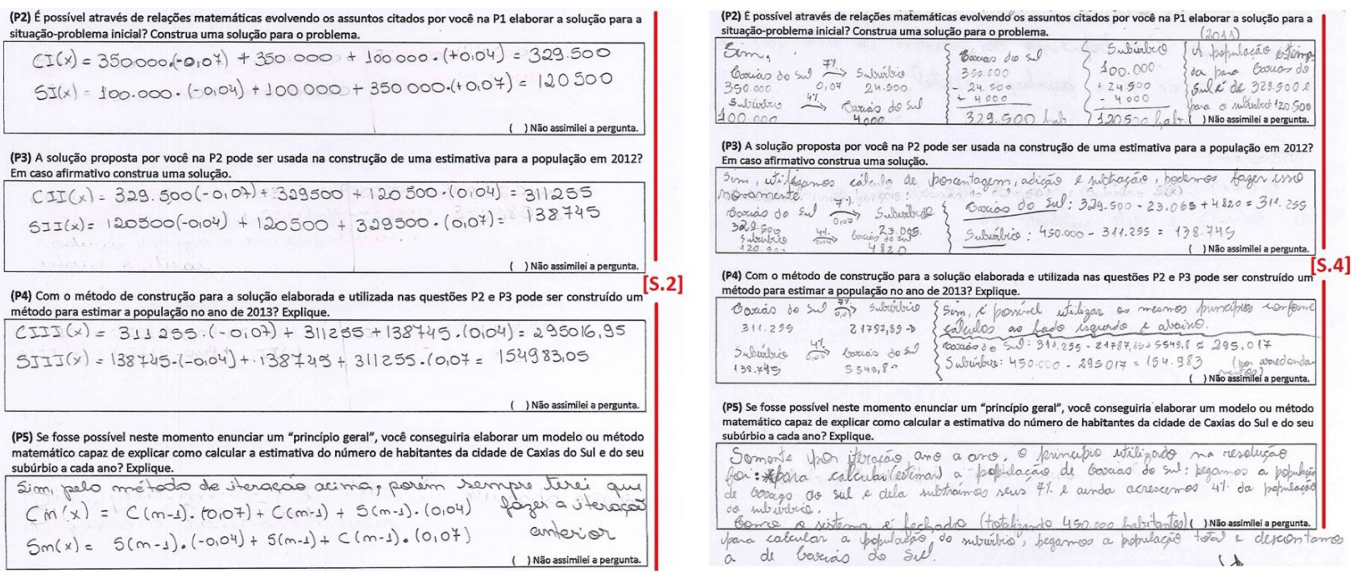

Fonte: Silva (2015, p. 115).

Quanto às soluções expostas pelos dois grupos (ensino médio e ensino superior) para a mesma situação-problema, considerações envolvendo abstração e tomada de consciência devem ser feitas. Primeiramente, diante de uma situação nova que se impõe ao sujeito, é necessário mobilizar diferentes esquemas e estruturas de pensamento que possam agir na elaboração de 
regulações ativas, as quais são ferramentas necessárias para o aperfeiçoamento de estruturas e para a construção de novos esquemas, já melhorados em relação aos pré-existentes. Isso nos permite afirmar que as respostas para um possível princípio geral, enunciadas pelos sujeitos no momento do terceiro experimento, demonstram que, ao experimentar o problema, por meio dos cálculos de estimativas, os sujeitos puderam inferi-las a partir das relações que eles próprios construíram entre as distintas etapas do fenômeno estudado. A capacidade de relacionar ações ou ideias aparentemente isoladas é uma atividade cognitiva essencial do sujeito, e possível, devido à evolução da abstração e da tomada de consciência ao longo de um determinado processo.

Em segundo lugar, a evolução da abstração e da tomada de consciência por parte do sujeito está fortemente relacionada com a ação e com a coordenação das ações sobre os objetos, sejam materiais ou mentais, em estudo. Isso significou, na época, para nós, pesquisadores, que uma hipótese aceitável fosse de que - pelo fato de o sujeito estar frequentando a disciplina de Modelagem Matemática, alocada no oitavo semestre do curso de Licenciatura em Matemática da instituição pesquisada - já tivesse sido oportunizado aos estudantes vivenciar situações e encarar (superando ou não) os desafios ao longo do curso de graduação. Tais oportunidades, ao serem convertidas em trabalho cognitivo, possibilitaram-lhes que a tomada de consciência e a abstração se aperfeiçoassem em níveis cada vez mais elaborados e complexos, possibilitando ao sujeito evoluir qualitativamente suas formas e estruturas de pensamento.

O quarto dia de atividades foi organizado em dois momentos: no primeiro, ocorreu a discussão acerca do vetor estacionário para a situação-problema da migração entre dois lugares. No segundo momento, foi apresentada uma segunda situação-problema envolvendo níveis de audiência de dois canais concorrentes A e B.

Quanto à primeira parte da aula, durante a manipulação do objeto virtual Cadeia de Markov-2D, os estudantes puderam verificar empiricamente se a sequência de vetores construída no problema convergia para um vetor limite, denominado vetor estacionário ou de equilibrio. Diferentemente dos estudantes do ensino médio no experimento dois, no terceiro experimento os sujeitos já conheciam técnicas matemáticas para realizar a construção do vetor estacionário. As técnicas matemáticas serviriam para confirmar as hipóteses formuladas antecipadamente. No que se refere à construção da hipótese sobre o vetor estacionário, os estudantes conseguiram, pelo uso do objeto virtual, determinar um possível candidato. A confirmação foi possível devido ao desenvolvimento de técnicas e mobilização de conhecimentos matemáticos sobre sistemas lineares. Um exemplo é mostrado na Figura 4.

É necessário refletir sobre a construção conceitual do vetor estacionário pelos estudantes envolvidos nesta etapa da sequência de atividades. Os estudantes do ensino médio, ao construir empiricamente uma possibilidade para vetor estacionário, não tinham as ferramentas ou os recursos necessários para que a sua hipótese fosse, de fato, verificada. Isso implicou que o conhecimento sobre esse conceito tenha sido elaborado por meio de observações pseudo-empíricas fundamentadas na visualização geométrica dos vetores resultantes. Mesmo sem conhecer o conceito de limite, em especial o de limite para uma sequência de vetores, os estudantes do ensino médio fizeram uso deste, na forma de uma possível regulação ativa para argumentar e compreender os fatos observados na situação imposta. $\mathrm{Na}$ medida do possível, devido às estruturas construídas até o momento pelos sujeitos do experimento dois (ensino médio), verificou-se que, de fato, eles também fizeram construções conceituais de matemática, dentro dos limites e possibilidades cognitivas estruturais em que cada um se encontrava. 
Silva, R. S.; Barone, D. A. C.; Basso, M. V. A.

Figura 4. Hipóteses e obtenção do vetor estacionário por [S.5]

(Ob2) Analisando a evolução do sistema através do objeto virtual é possivel afirmar que a partir de certo tempo as populações da cidade e do subúrbio irão se estabilizar?? Explique.

Sim, com vo aumento de p, ou sejo, como decorrer dos onos e expecificomentu e partir do ane 2119, a populoçád se estaliliza, considerando a parte intive descrite pelo seftuare, ua populoçáuna cidade será.

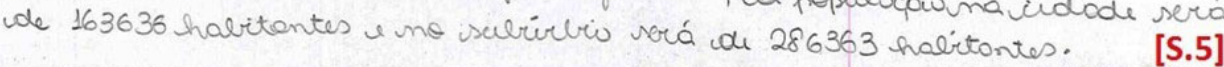

(Ob4) Faça uma hipótese através do objeto de quem poderia ser o vetor estacionário para a situação-problema. Utilize os seus conhecimentos de sistemas lineares para calcular o vetor. Justifique.

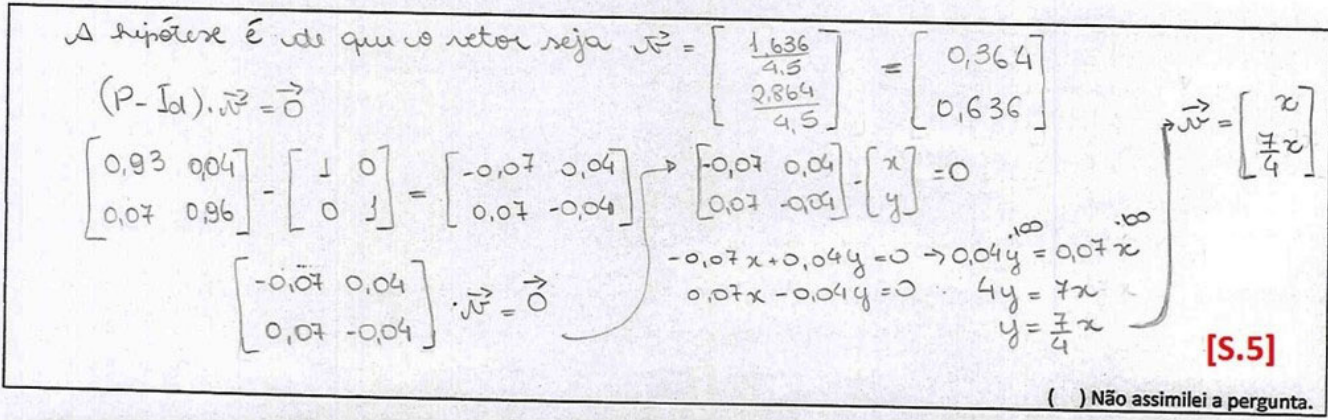

Fonte: Silva (2015, p. 124).

Ao verificar o encaminhamento dado pelos sujeitos do terceiro experimento para a questão envolvendo o vetor estacionário, percebe-se o aperfeiçoamento na qualidade de pensamento, principalmente quanto às formas de superar os impasses e desafios impostos pelo objeto do conhecimento. Notou-se que a construção/validação/reformulação das hipóteses foi potencializada pelo uso do objeto virtual, pois, ao modificar os parâmetros no objeto e observar instantaneamente o que as modificações implicavam, isso poderia contribuir com alterações.

O segundo momento do quarto encontro consistiu em apresentar e abordar uma situação-problema envolvendo os níveis de audiência de dois canais concorrentes A e B na cidade de Caxias do Sul (RS). Novamente, os estudantes foram questionados acerca da idealização ou não da situação para fins da modelagem. Os argumentos dos estudantes foram os mais diversificados, porém convergentes na ideia do "sim"; a situação-problema apresentava-se ideal para fins de uma possível modelagem. Nas palavras dos estudantes:

[S.1]: "Sim, pois podemos transformá-lo em um problema matemático e resolvê-lo utilizando a linguagem matemática".

[S.2]: "Sim, pois não está levando todas as possiveis causas da situação".

[S.3]: "Sim, pois podemos representá-lo através de relações matemáticas".

[S.4]: "Sim, por desconsiderar-se outras situações que poderiam afetar os cálculos. Por exemplo, o programa que está passando, o horário do mesmo,...”. 
[S.5]: "Sim, pois podemos descrevê-lo através de relaçoes matemáticas".

[S.6]: "Sim, pois não está levando em consideração todas as possivieis variáveis que podem interferir na audiência".

Situação-problema sobre os níveis de audiência adaptado de Anton e Rorres (2012).

Suponha que às $10 \mathrm{~h}$ em Caxias do Sul cada um dos dois canais de televisão con-
correntes (A e B) tenha 150.000 telespectadores de audiência. Considerando que
a cada hora que passa o canal A atrai $10 \%$ da audiência do canal B e que o canal
B atrai $20 \%$ da audiência do canal A. Com o passar das horas, a partir das 10h, é
possível prever os níveis de audiência em cada um dos canais de televisão utilizando
a ideia da Cadeia de Markov.

Neste segundo momento do encontro, o objeto virtual Cadeia de Markov - 2D foi utilizado para a construção de um possível modelo matemático, inspirado nas Cadeias de Markov. Foram também construídos pelos estudantes os vetores probabilidade e a matriz estocástica relativos ao problema.

Os estudantes conseguiram elaborar um princípio ou regra geral para o funcionamento da segunda situação-problema proposta, construindo também uma hipótese sobre um candidato a vetor estacionário e, a partir de conhecimentos envolvendo sistemas lineares, puderam, por um processo validar, suas hipóteses. Durante a elaboração do princípio matemático envolvendo as situações estudadas, possivelmente o aperfeiçoamento da qualidade de pensamento dos sujeitos tenha ocorrido e seja o resultado das sucessivas operações de reflexão e reflexionamento, as quais oportunizaram ao sujeito avançar na direção dos patamares superiores de abstração e tomadas de consciência de maior qualidade. Logo, da união da reflexão e do reflexionamento constituiu-se uma estrutura capaz de não apenas passar de um nível para o seguinte, mas de juntas terem o caráter de uma estrutura capaz de desenvolver características qualitativas superiores no decorrer das passagens, ou também consideradas projeções. Isso significa que o patamar superior alcançado pelo sujeito, por meio da ação e coordenação de ações, possui relação intrínseca com os patamares inferiores ou iniciais desenvolvidos através da ação. Nesse caso, pode-se afirmar que a reorganização e coordenação das ações, mentais ou materiais, permitiram aperfeiçoar, cada vez mais, a ação na tentativa de compreender os objetos em estudo, ou seja, durante a elaboração do princípio matemático, ocorreu a evolução da abstração reflexionante, que foi um processo pelo qual cada sujeito construiu, reconstruiu, organizou e reorganizou os seus esquemas e estruturas de pensamento.

Pôde-se inferir, ao final da sequência de atividades, que o processo de construção do conhecimento envolvendo a temática em estudo tenha sido consolidado pelos participantes do estudo, uma vez que se percebeu o envolvimento dos sujeitos em suas ações, materiais ou mentais, sobre os diversos objetos em investigação. 


\section{Considerações (nem tão) finais}

A partir da ideia de abordar situações-problema que envolvessem e relacionassem o tripé Modelagem Matemática - Cadeias de Markov - Tecnologias Digitais, delineou-se como objetivo principal da tese de doutorado pesquisar como os processos da tomada de consciência e abstração reflexionante influenciam a elaboração e o desenvolvimento do pensamento ao utilizar objetos virtuais na investigação de situações-problema que envolvessem modelagem matemática com Cadeias de Markov. Ao todo, foram realizados três experimentos didáticos e, no presente artigo, foi exposto um recorte do terceiro, o qual envolveu estudantes da graduação em Licenciatura em Matemática. Considera-se que as reflexões finais aqui expostas não encerram por definitivo o assunto explorado por meio da pesquisa, e sim faz-se um convite para que demais professores, pesquisadores e interessados no tema reflitam sobre a melhoria na qualidade das aulas de matemática. A atual demanda no cenário educacional brasileiro faz a academia dar-se conta de que não é mais suficiente formar de modo inicial um professor de matemática que priorize a reprodução dos conteúdos e não reflita sobre eles. Emerge, a partir do cenário educacional, a necessidade de que o professor seja cada vez mais reflexivo e construtor de conhecimentos, primeiro para ele próprio e também junto dos seus estudantes em sala de aula. Logo, acredita-se que os aspectos debatidos neste trabalho de tese, com foco no terceiro experimento didático realizado, certamente têm implicações no futuro trabalho docente dos sujeitos participantes da pesquisa.

Quanto aos resultados obtidos com a realização da Engenharia Didática - por meio da construção, aplicação e análise da sequência de atividades junto aos estudantes da Licenciatura em Matemática -, verificou-se a aderência da pesquisa ao pensamento de Lopes, Alves e Ferreira (2015, p. 570) que expõem: "Ao tentar encontrar uma maneira de solucionar os problemas - no caso os exercícios propostos - os estudantes sentiram-se desafiados, e isso os motivou durante a atividade." No caso do experimento didático realizado, os desafios impostos a cada atividade forçaram os participantes a desenvolver métodos e um processo para a resolução das situações-problema, que foram o resultado de esforços cognitivos ocorridos por meio de reflexões, reflexionamentos e regulações ativas.

Como reflexão pertinente, cabe mencionar que, ao considerar a matemática uma ciência construída a partir do esforço humano e em constante evolução e aperfeiçoamento, a proposta de investigação de situações-problema e de contextos da realidade oportunizou aos envolvidos construir para si sua própria matemática. Ou seja, ao desafiar os discentes na produção de matemática, foi-se além da construção de conceitos; foi possível que os estudantes se conscientizassem do seu papel colaborativo enquanto sujeitos inseridos na vida em sociedade.

Ao fazer uma leitura sobre os conceitos de Epistemologia Genética de Piaget e usá-la como fundamentação para a construção do conhecimento, considera-se que tal teoria explicou satisfatoriamente o fato de os sujeitos aperfeiçoarem a qualidade de seu pensamento por meio da sucessiva ação e coordenação das mesmas sobre os objetos em investigação, sejam materiais ou mentais. Após a realização do terceiro experimento didático, durante a análise das produções, foi possível relacionar a construção do conhecimento matemático dos sujeitos com conceitos da Epistemologia Genética. Constatou-se que tais conceitos constituíram uma fundamentação teórica necessária e suficiente para auxiliar-nos na interpretação dos registros escritos, fornecendo-nos os subsídios necessários para verificar o gradual e processual avanço dos participantes na direção do aumento do conhecimento ou da capacidade cognitiva. 
Quanto ao uso dos recursos tecnológicos utilizados durante o experimento, foi possível observar o potencial desenvolvimento das mais variadas formas de pensamento, possibilitando aos envolvidos criar conjecturas e hipóteses. Notou-se que, a partir da exploração dos objetos virtuais, os sujeitos puderam visualizar, validar ou refutar, de modo dinâmico, as hipóteses. A cada modificação na tela do computador - via mudança dos parâmetros, por exemplo -, observou-se uma reorganização por parte dos sujeitos, provinda da reflexão ocorrida já em um patamar cognitivo superior, fazendo que houvesse o estabelecimento de novas abstrações que influenciaram a formação de novas hipóteses, as quais avançaram de modo dinâmico e iterativo, promovendo a reorganização ou reestruturação do pensamento.

Finalmente, acredita-se que, em nenhum momento, o trabalho de tese intencionou ou propôs algum tipo de "salvacionismo" ou solução para os problemas que existem (e persistem) no ensino da matemática. Ao contrário, procurou-se, mediante uma construção teórica, mostrar de que forma a Tecnologia Digital contribuiu para a elaboração e construção de conceitos matemáticos envolvendo Modelagem Matemática com Cadeias de Markov, fazendo-se uso de sequências de atividades. Evidenciou-se - por meio do diálogo entre Tecnologias Digitais, Modelagem Matemática, Cadeias de Markov, Engenharia Didática e Epistemologia Genética aderência e convergência entre as possibilidades e potencial para a construção dos conceitos. Tais conceitos se consolidaram como resultado de um processo complexo, correlacionado e com uma infinidade de relações entre os cinco elementos antes elencados.

\section{Referências}

ALLEVATO, N. S. G. Associando o computador à resolução de problemas fechados: análise de uma experiência. 2005. Tese (Doutorado em Educação Matemática) - Instituto de Geociências e Ciências Exatas, Universidade Estadual Paulista, Rio Claro, 2005.

ALMEIDA, L. W.; SILVA, K. P.; VERTUAN, R. E. Modelagem matemática na educação básica. São Paulo: Contexto, 2012.

ANTON, H.; BUSBY, R. C. Contemporary algebra. Hoboken: Wiley, 2003.

ANTON, H.; RORRES, C. Álgebra linear com aplicações. 10. ed. Porto Alegre:

Bookman, 2012.

ARAÚJO, J. L. Cálculo, tecnologias e modelagem matemática: as discussões dos alunos. 2002. Tese (Doutorado em Educação Matemática) - Instituto de Geociências e Ciências Exatas, Universidade Estadual Paulista, Rio Claro, 2002. Disponível em: < http://www.mat. ufmg.br/ jussara/tese/tese.pdf>. Acesso em: 17 ago. 2018.

ARTIGUE, M. Engenharia didática. In: BRUN, J. Didáctica das matemáticas. Lisboa: Instituto Piaget: Horizontes Pedagógicos, 1996. p. 193-217.

BECKER, F. Abstração pseudo-empírica e reflexionante: significado epistemológico e educacional. Schème: revista eletrônica de psicologia e epistemologia genéticas, Marília, v. 6, n. esp., p. 104-128, 2014. 
BEHRENDS, E. Introduction to Markov chains: with special emphasis on rapid mixing. Berlin: Vieweg, 2000.

BORSSOI, A. H. Modelagem matemática, aprendizagem significativa e tecnologias: articulações em diferentes contextos educacionais. 2013. Tese (Doutorado em Ensino de Ciências e Educação Matemática) - Universidade Estadual de Londrina, Londrina, 2013.

D’AMBROSIO, U. Educação matemática: da teoria à práxis. Campinas: Papirus, 1996.

BRASIL. Ministério da Educação. Conselho Nacional de Educação. Diretrizes curriculares nacionais para a formação inicial e continuada dos profissionais do magistério da educação básica. Diário Oficial da União, Brasillia, 25 jun. 2015. Seção 1, p. 13. Disponível em: <https:/ / tinyurl.com/y87q9jimg>. Acesso em: 17 ago. 2018.

BRASIL. Ministério da Educação. Secretaria de Educação Básica. Diretrizes curriculares nacionais gerais da educação básica. Brasília, 2013.

LOPES, L. S.; ALVES, G. L. P.; FERREIRA, A. L. A. A simetria nas aulas de matemática: uma proposta investigativa. Educação \& Realidade, Porto Alegre, v. 40, n. 2, p. 549-572, 2015.

MALHEIROS, A. P. S. A produção matemática dos alunos em um ambiente de modelagem. 2004. Dissertação (Mestrado Educação Matemática) - Instituto de Geociências e Ciências Exatas, Universidade Estadual Paulista, Rio Claro, 2004.

PIAGET, J. Abstração reflexionante: relações lógico-aritméticas e ordem das relações espaciais. Porto Alegre: Artes Médicas, 1995.

PIAGET, J. Fazer e compreender. São Paulo: Edusp: Melhoramentos, 1978.

PIAGET, J. A tomada de consciência. São Paulo: Edusp: Melhoramentos, 1977.

POWELL, A. B. Construção colaborativa do conhecimento tecnológico, pedagógico e do conteúdo de professores de matemática. Boletim GEPEM, Rio de Janeiro, n. 64, p. 1-15, 2014.

SILVA, R. S. Cadeias de Markov e modelagem matemática: da abstração pseudoempírica à abstração refletida com uso de objetos virtuais. 2015. Tese (Doutorado em Informática na Educação) - Universidade Federal do Rio Grande do Sul, Porto Alegre, 2015.

SOARES, D. S. Uma abordagem pedagógica baseada na análise de modelos para alunos de biologia: qual o papel do software? 2012. Tese (Doutorado em Educação Matemática) - Instituto de Geociências e Ciências Exatas, Universidade Estadual Paulista, Rio Claro, 2012.

SOISTAK, A. V. Uma experiência com a modelagem matemática no ensino médio profissionalizante. In: BRANDT, C. F.; BURAK, D.; KLÜBER, T. E. (Org.). Modelagem matemática: uma perspectiva para a educação básica. Ponta Grossa: Editora UEPG, 2010. p. $107-130$. 
TALL, D. Technology and cognitive growth in mathematics. In: CONFERENCE ON MATHEMATICS AND NEW TECHNOLOGIES, 1999, Thessaloniki. Disponível em: <https://www.researchgate.net/publication/247705096_Technology_and_Cognitive_ Growth_in_Mathematics>. Acesso em: 17 ago. 2018.

TALL, D. Using the computer as an environment for building and testing mathematical concepts: a tribute to Richard Skemp. [1986]. Disponível em: <https:// homepages.warwick.ac.uk/staff/David.Tall/pdfs/dot1986h-computer-skemp.pdf $>$. Acesso em: 17 ago. 2018.

TALL, D.; DUBINSKY, E. Advanced mathematical thinking and the computer. In: TALL, D. O. (Org.). Advanced mathematical thinking. Dordrecht: Kluwer, 1991. p. 231-248. 